\title{
1 A review of the application of the fetch effect to modelling sand supply to \\ 2 coastal foredunes
}

4 Irene Delgado-Fernandez

$5 \bullet$

6 Department of Geography, University of Guelph, Guelph, Ont., Canada

\section{Abstract}

9 The fetch effect is an increase of the aeolian sediment transport rate with distance

10 downwind over an erodible surface. The first observations of the fetch effect go

11 back 70 years and the concept has been widely used in a variety of landscapes.

12 This paper reviews the present state of knowledge of the fetch effect, with

13 particular reference to its application in coastal areas, and compares findings from

14 theoretical, wind tunnel, and fieldwork experiments. While wind tunnel experiments

15 tend to show critical fetch distances of a few metres, studies in natural areas show

16 that measured critical fetch distance can exceed one hundred metres. There is

17 supporting evidence pointing to the role of soil clods/crusts and moisture content in

18 increasing critical fetch distances in agricultural and coastal areas, respectively. In

19 coastal areas tradeoffs imposed by the geometry of the beach over which the wind

20 is blowing and wind direction determine the available fetch distance and thus the

21 sediment transport rate downwind. A major challenge which needs to be

22 addressed is the development of robust equations for predicting both the critical

23 fetch length and the increase in the sediment transport rate with distance on

24 beaches. There is also a need to obtain field data on the combined effect of 
25 moisture, angle of wind approach, beach width, and fetch length. Long-term

26 monitoring using remote sensing techniques may provide valuable data to analyze

27 the effect of fetch distances on the nature of transport events that deliver sediment

28 from the beach to the foredune.

\section{Keywords}

31 Saltation; Equilibrium; Disequilibrium; Sediment transport predictions; Meso-scale

\section{Abbreviations}

$\alpha$ - angle of deviation of prevailing wind direction from right angle to the dune line or to the field strip (e.g., $\alpha=0$ during onshore winds) $\rho$ - air density $\left(1.22 \mathrm{~kg} \mathrm{~m}^{-3}\right)$ s- distance from the upwind margin of an erodible surface to the area where transport reaches $63.2 \%$ of the maximum transport (common definition of critical fetch distance or critical field length in agricultural areas c - perpendicular distance separating two parallel streamlines of the wind field C - proportionality coefficient that varies with the fetch length $(F)$ in Dong et al. (2004)

COG - combined residue factor in RWEQ $\Delta \mathrm{x}$ - increase in transport quantity across wind in RWEQ EF - erodible fraction in RWEQ F - fetch length; distance from the upwind margin of an erodible surface to a point of interest 
$F_{c}$ - critical fetch length; distance from the upwind margin of an erodible surface to the point where transport reaches a maximum value.

Researchers working in agricultural soils define the critical fetch distance

as $\mathrm{s}$

$F_{m}$ - maximum fetch length; maximum distance of erodible surface over

which the wind is blowing, determined by the angle of wind approach and the beach width (coastal areas) or the field length (agricultural soils)

g - acceleration due to gravity

$\mathrm{KN}$ - soil roughness factor in RWEQ

I - unit alongshore length at the dune line mapped out by two parallel streamlines of the wind field

$L$ - beach length

Q - sediment transport rate for a given wind speed

$Q_{C}$ - sediment transport rate at the end of the maximum fetch length (along cline)

$Q_{m}$ - maximum sediment transport rate for a given wind speed

$Q_{1}$ - sediment deposition per unit length of dune (along I)

$Q_{i}$ - transport quantity upwind in RWEQ

$\mathrm{Q}_{\mathrm{i}+1}$ - quantity of soil transported at a point $\times$ downwind from the upwind boundary in RWEQ

RWEQ - revised wind erosion equation

SCF - soil crust factor in RWEQ

SLR - single-lens reflex

$U$ - wind velocity 
$U_{t}$ - threshold wind velocity

WEQ - wind erosion equation

WF - weather factor in RWEQ

$W_{b}$ - beach width

$W_{f}$ - agricultural field width

x - distance along profile

\section{Introduction}

81

82 The fetch effect is an increase in the sediment transport rate (Q) with distance

83 downwind from a boundary marking the transition from a non-erodible to an

84 erodible surface (Chepil, 1957, Davidson-Arnott and Law, 1990, Stout,

85 1990, Gillette et al., 1996, Fryrear et al., 2000 and Dong et al., 2004). Under ideal

86 scenarios (steady wind, large sediment availability) the number of saltating

87 particles within the saltation cascade increases exponentially to a maximum

88 condition (Bauer and Davidson-Arnott, 2003). This maximum condition reflects

89 saturation of the system where sand movement carries all the vertical momentum

90 flux of the wind (Gillette et al., 1996) and when the transport rateQ becomes

91 independent of distance $\times$ ( Shao and Raupach, 1992). The distance from the

92 upwind boundary to a point of interest is the fetch distance, $F$, and the maximum

93 length of erodible surface over which the wind is blowing is the maximum fetch

94 distance, $F_{m}$. The distance necessary to achieve the maximum transport rate $\left(Q_{m}\right)$

95 associated with a particular wind speed is the critical fetch distance, $F_{c}$ ( Davidson-

96 Arnott and Dawson, 2001). ${ }^{1}$ 
97 The significance of the fetch effect has been explored in relation to wind erosion in

98 agricultural soils (e.g., Fryrear and Saleh, 1996), particle emission in arid and semi-

99 arid environments with patch vegetation (streets - see Okin et al., 2006), and

100 aeolian transport of sand from beaches to coastal dunes (e.g., Davidson-Arnott

101 and Law, 1990). In these areas, if $F_{m}<F_{c}$ for a given wind speed and surface

102 characteristics, then the amount of erosion will be less than predicted and the

103 transport rate at the downwind margin field boundary, street, or beach will be less

104 than that calculated by standard aeolian transport formulae. Thus, restricted beach

105 width, agricultural field dimension, or wind tunnel length have been identified as

106 potentially limiting our ability to observe the true maximum sediment transport with

107 strong winds, because critical fetch distances often exceed the available fetch

108 distance (Section 2).

109 In coastal areas, prediction of aeolian sediment transport remains unsolved at a

110 variety of temporal and spatial scales. Field measurements do not generally

111 correspond with predicted rates of sand flux or net deposition into the foredunes

112 (Davidson-Arnott and Law, 1996 and Arens, 1997). Most of the attention over the

113 last decades has focused on identifying supply-limiting factors (Nickling and

114 Davidson-Arnott, 1990) because they decrease the number of grains that become

115 part of the saltation system and thus reduce the equilibrium transport rate. Many

116 excellent reviews exist on the effects of moisture, particle size and sorting, surface

117 crusts, or other supply-limiting conditions (Pye, 1983,Horikawa et al.,

118 1986, Nickling, 1994, Namikas and Sherman, 1995 and Cornelis and Gabriels,

119 2003; etc.). However, the disequilibrium between the wind flow and sediment

120 transport rate characteristic of most field situations introduces significant problems 
121 when applying deterministic formulae to predicting sediment movement.

122 Disequilibrium may occur in time (e.g., due to wind unsteadiness), in space (e.g.,

123 influence of topographic form), or, as is the case of the majority of transport

124 systems, both in time and in space (Table 1). The fetch effect is a particular case of

125 a disequilibrium situation with only spatial controls. In the simplest case of a steady

126 wind blowing over an ideal surface, the fetch effect introduces disequilibrium

127 between the transport rate and the wind field up to a distance $\left(F_{c}\right)$ where maximum

128 transport is achieved. In general terms, formulae developed to predict sediment

129 transport are applicable to the equilibrium situation that exists beyond this distance.

130 As wind speed or the effect of supply-limiting factors increase so do corresponding

131 critical fetch distances (Section 3.2), and thus the area where traditional formulae

132 will overpredict the actual transport rate.

134 Table 1.Contextualization of the fetch effect and other factors causing temporal

135 and spatial equilibrium and disequilibrium in transport systems (only a few

136 examples of publications are including here for practical purposes).

Transport systems

\begin{tabular}{ll}
\hline $\begin{array}{l}\text { Equilibrium } \\
\text { (transport rate in } \\
\text { equilibrium with } \\
\text { applied stress) }\end{array}$ & $\begin{array}{l}\text { Transport- } \\
\text { limited } \\
\text { (surface } \\
\text { provides } \\
\text { unlimited } \\
\text { grains) }\end{array}$ \\
& Supply- \\
& limited \\
& (surface \\
ability to \\
supply grains \\
is limited)
\end{tabular}

\begin{tabular}{l|lll} 
Disequilibrium & Transport- Unsteady Fetch effect, & Butterfield, 1999, Dong
\end{tabular}
Space $\quad$ Example of studies

Dry, non-cohesive Bagnold, and uniform 1941, Kawamura, sediment; flat 1951 and Lettau and surface Lettau, 1977

Steady flow

Homogeneous moisture, bounding agents, roughness elements, particle size and sorting, slope, etc.

Horikawa et al., 1986, Iversen and Rasmussen, 1994, Lancaster, 1981, Logie, 1982 and Nickling and Ecclestone, 1981 
Transport systems

\begin{tabular}{|c|c|c|c|c|}
\hline \multirow{3}{*}{$\begin{array}{l}\text { (transport rate } \\
\text { variable and in } \\
\text { disequilibrium with } \\
\text { wind field) }\end{array}$} & & Time & Space & Example of studies \\
\hline & $\begin{array}{l}\text { limited } \\
\text { (surface has } \\
\text { the potential } \\
\text { to provide } \\
\text { unlimited } \\
\text { grains) }\end{array}$ & $\begin{array}{l}\text { flow, wind } \\
\text { ramp- } \\
\text { up/down }\end{array}$ & $\begin{array}{l}\text { boundary layer } \\
\text { development }\end{array}$ & $\begin{array}{l}\text { et al., 2004, Spies and } \\
\text { McEwan, } \\
2000 \text { and Stout and } \\
\text { Zobeck, } 1997\end{array}$ \\
\hline & $\begin{array}{l}\text { Supply- } \\
\text { limited } \\
\text { (surface } \\
\text { ability to } \\
\text { supply grains }\end{array}$ & \multicolumn{2}{|c|}{$\begin{array}{l}\text { Spatial and temporal variations of } \\
\text { supply-limiting factors (moisture, } \\
\text { crusts, topography, etc.), flow, } \\
\text { and fetch }\end{array}$} & $\begin{array}{l}\text { Bauer et al., } \\
\text { 2009,Davidson-Arnott } \\
\text { and Bauer, } \\
2009 \text { and Walker et al., } \\
2006\end{array}$ \\
\hline
\end{tabular}

138 This paper critically reviews the evidence for the fetch effect, the mechanisms that 139 may produce it, and the problems that remain to be resolved in incorporating it into

140 models predicting aeolian sediment transport in complex environments. While the

141 focus of attention is directed towards aeolian transport on beaches, it also draws

142 on material from agricultural soils and semi-arid environments. Theoretical, wind

143 tunnel, and fieldwork studies are analyzed to determine the physics of aeolian

144 entrainment and transport processes that could provide an explanation for long

145 fetch distances (Section 3). The linkage between the fetch effect and supply-

146 limiting factors such as moisture content is examined in light of recent findings

147 suggesting the interaction between both as a primary control of sand transport on

148 beaches (Davidson-Arnott et al., 2008 and Bauer et al., 2009). The abundant

149 literature on agricultural fields provides a background to develop deterministic

150 equations that include the fetch effect in coastal areas, together with the results of

151 wind tunnel (e.g., Dong et al., 2004) and field experiments (Davidson-Arnott et al.,

152 2008). However, a major challenge remains on how to incorporate knowledge of

153 the fetch effect into a model that could be used to predict sediment input to the 
154 foredunes at the meso-scale (Section 5). Remote sensing techniques provide

155 effective tools for measuring the combined effect of important key variables such

156 as moisture, beach width, and fetch distances over a number of transport events

157 through the year (Lynch et al., 2006, Darke et al., 2009 and Delgado-Fernandez

158 and Davidson-Arnott, 2009) (Section6). Theoretical frameworks (Bauer and

159 Davidson-Arnott, 2003) can be implemented to analyze assumptions surrounding

160 the geomorphological impacts of these events. If the fetch effect plays an important

161 role in controlling the magnitude of transport toward the foredunes, then its

162 incorporation into modelling will improve predictions of aeolian transport rates and

163 sediment budget calculations in coastal areas.

\section{Evidence for the existence of the fetch effect}

2.1. Wind tunnel experiments and numerical simulations

168 Wind tunnel studies differ from fieldwork results in the numerical characterization of

169 the fetch effect, and suggest shorter critical fetch distances (a few metres) than

170 those reported in natural areas (from tens of metres to over hundreds of metres).

171 However, a number of authors have reported on critical fetch distances longer than

172 the length of the wind tunnel. Bagnold (1941) suggested the need for a minimum

173 length of $9 \mathrm{~m}$ to attain equilibrium between the wind flow and saltation. Shao and

174 Raupach (1992) found that their $10 \mathrm{~m}$ long wind tunnel did not allow the

175 stabilization of saltation and they built a second wind tunnel of $17 \mathrm{~m}$, which was still

176 too short to observe the final equilibrium state of transport with high wind velocities.

177 Laboratory analysis by Dong et al., 2002 and Dong et al., 2004 confirmed the 
178 positive relationship between increasing wind velocity, fetch distance, saltation

179 height, and both vertical and horizontal flux. They found that as wind speed

180 increases more grains travel at a greater height and further downwind with the

181 distance required to achieve equilibrium also increasing (a phenomena previously

182 observed in agricultural soils - Section 2.2). Similar to Shao and Raupach (1992),

183 equilibrium transport was not reached for strong winds within the $16 \mathrm{~m}$ long wind

184 tunnel ofDong et al. (2004). That is, even under ideal transport-limited conditions in

185 laboratory settings, critical fetch distances may be larger than tens of metres.

186 Additionally, wind tunnel experiments may be in fact substantially underestimating

187 critical fetch distances. The small vertical dimension characteristic of most wind

188 tunnels interferes with the flow and constrains the full vertical development of an

189 internal boundary layer seeking its natural equilibrium at some distance

190 downstream. The vertical distribution of shear within the profile is artificially

191 "forced", which anticipates the adjustment of saltation (Bauer et al., 2004).

192 Numerical simulations on the length required to achieve a steady state by Spies

193 and McEwan (2000) suggest that critical fetch distances can reach up to $50 \mathrm{~m}$ or

194 more (depending on wind speed) when the effects of gusts and wind turbulence

195 are included.

196 Fig. 1 and Table 2 compare results by (A) Shao and Raupach (1992) (wind tunnel)

197 andDavidson-Arnott and Law (1990) (field experiment), and (B) Dong et al.

198 (2004) (wind tunnel) and Spies and McEwan (2000) (numerical simulation). Note

199 that the maximum wind speed reported by Shao and Raupach (Fig. 1A) is

$20012.5 \mathrm{~m} \mathrm{~s}^{-1}$, which is one of the lowest wind speeds considered by Dong et al. (Fig.

201 1B). Fig. 1 is solely used here to analyze in general terms the differences in curve 
202 shape and distances and not for transport magnitudes. Curves are reproduced

203 from original graphs and tables, and transport flux quantities have been normalized

204 by each of the maximum values reported in the corresponding publications.

205 Caution is required regarding the true maximum transport value because critical 206 fetch distances may be greater than those reported here. Shao and Raupach's

207 experiments show an overshoot centred at 5-7 $\mathrm{m}$. The overshoot is characterised

208 by a rapid increase of $Q$ with distance to a maximum condition followed by a

209 decrease to a lower equilibrium value ( Shao and Raupach, 1992). The overshoot

210 is also predicted by Spies and McEwan, but their simulations suggest that

211 increases in wind speed produce longer distances for both maximum and

212 equilibrium transport values. The overshoot is not evident in other wind tunnel

213 studies (e.g., Dong et al., 2004) nor has it been observed in field measurements in

214 agricultural fields and on beaches (e.g., Stout, 1990, Davidson-Arnott and Law,

2151990 and Davidson-Arnott et al., 2008). The experiments by Davidson-Arnott and

216 Law and Dong et al. confirm the presence of longer critical fetch distances with

217 higher wind speeds. While the $F_{c}$ associated with winds less than $12 \mathrm{~m} \mathrm{~s}^{-1}$ are

218 negligible in the study by Dong et al., Davidson-Arnott and Law report on $F_{c}$ up to

$21930 \mathrm{~m}$ at much lower wind speeds of $8.3 \mathrm{~m} \mathrm{~s}^{-1}$.

220

221 Table 2. Summary of numerical values reported by authors listed in Fig. 2. Wind

222 speeds for Spies and McEwan (2000) have been calculated from effective friction

223 velocities reported by the authors following the Law of the Wall $\left(U=\ln \left(z / z_{0}\right) U * / k\right)$,

224 and assuming a grain size of $0.25 \mathrm{~mm}$. 


\begin{tabular}{|c|c|c|c|}
\hline Publication & $\begin{array}{l}\text { Wind speed } \\
\text { range }\left(\mathrm{m} \mathrm{s}^{-1}\right)\end{array}$ & Fetch distances range (m) & $\begin{array}{l}\text { Sediment size } \\
(\mathrm{mm})\end{array}$ \\
\hline $\begin{array}{l}\text { Davidson-Arnott and } \\
\text { Law (1990) }\end{array}$ & $5.9-13.8$ & $10-15$ to $>35$ & $0.2-0.33$ \\
\hline \multirow{3}{*}{$\begin{array}{l}\text { Shao and Raupach } \\
\text { (1992) }\end{array}$} & \multirow[t]{3}{*}{$8.5-12.5$} & Length to overshoot $=5$ & \multirow[t]{3}{*}{0.2} \\
\hline & & Length to equilibrium $>17$ & \\
\hline & & $\begin{array}{l}\text { Minimum distance for } \\
\text { equilibrium }=15\end{array}$ & \\
\hline Dong et al. (2004) & $8-22$ & Negligible to $>16$ & 0.18 \\
\hline $\begin{array}{l}\text { Spies and McEwan } \\
(2000)\end{array}$ & $7.9-26.9$ & Length to overshoot $=5$ to 30 & 0.25 \\
\hline
\end{tabular}

226 2.2. Field experiments

227 2.2.1. Agricultural soils

228 The fetch effect was identified early in the twentieth century as a primary control for

229 wind erosion in agricultural fields (Chepil and Milne, 1939), and gained major

230 attention especially after environmental issues associated with the Dust Bowl of the

231 1930s in the Great Plains of North America (Hansen and Libecap, 2004). The

232 number of publications dedicated to soil erosion in agricultural fields is rather

233 extensive, and a considerable number of them include the role of field dimensions

234 (e.g., Chepil et al., 1964, Lyles, 1977,Fryrear and Saleh, 1996 and Fryrear et al.,

235 2000). Critical fetch distances of up to $150 \mathrm{~m}$ during wind erosion episodes have

236 been observed (Fryrear and Saleh, 1996 and Gillette et al., 1996) and even more

237 than $300 \mathrm{~m}$ (Stout, 1990). The critical fetch distance has also been found to vary

238 with height above the bed. Horizontal lengths needed to attain maximum transport

239 were larger at 1 and $1.65 \mathrm{~m}$ than at 0.15 and $0.25 \mathrm{~m}$ heights in experiments carried

240 out by Stout, 1990 and Stout and Zobeck, 1996, respectively.

241 The inclusion of fetch distances in modelling transport rates in agricultural areas

242 dates back to Chepil (1957), who linked the length of the field over which the wind 
243 is blowing with the growth of the transport cloud. The Wind Erosion Equation

244 (WEQ) proposed byWoodruff and Siddoway (1965) was adapted to design controls

245 against erosion, where the amount of sediment removed from a given field could

246 be calculated using field length, prevailing wind erosion direction, and soil,

247 vegetation and climatic factors. In an attempt to include new inputs such as

248 sediment transported in suspension, Fryrear et al. (2000)reviewed the WEQ and

249 tested the improved Revised Wind Erosion Equation (RWEQ) computer program

250 against measured erosion from 22 different sites. ${ }^{2}$ The quantity of soil transported

251 at a point $x$ downwind $\left(Q_{i+1}\right)$ is expressed in RWEQ as:

252

$$
Q_{i+1}=Q_{i}+\left(\frac{Q_{m}-Q_{i}}{s}\right) \frac{2 x}{s} \Delta x
$$

254 where $Q_{i}$ is the transport quantity upwind and $\Delta x$ stands for an increase in

255 transport quantity across. The distance from the upwind margin of an erodible

256 surface to the area where transport reaches $63.2 \%$ of the maximum transport is the

257 critical fetch length $\mathrm{s} . \mathrm{Q}_{\mathrm{m}}$ is the maximum transport capacity for a given wind over a 258 specific soil and is computed as:

259

$$
Q_{\mathrm{m}}=109.8+(W F \times E F \times S C F \times K N \times C O G)
$$

261 where $\mathrm{WF}=$ weather factor, $\mathrm{EF}=$ erodible fraction, $\mathrm{SCF}=$ soil crust

262 factor, $\mathrm{KN}=$ soil roughness factor, and $\mathrm{COG}=$ combined residue factor. Each of

263 these factors is calculated based on a number of surface and environmental 
264 variables (for details seeFryrear et al., 2000), and field shape, size, and orientation 265 are included in the management input files.

266 Based on the assumption that wind erosion-processes are naturally controlled by a

267 self-balancing mechanism, Stout (1990) derived and tested in the field a simple

268 equation to describe the variation of sediment flux with distance:

269

$270 \quad q / Q_{m}=1-e^{(-x / b)}$

271

272 As described in Section 2.1, both $Q_{m}$ and $s$ depend on height. Fig. 2 compares the

273 increase of transport with distance for one prediction carried out with RWEQ 274 (extracted from Fryrear et al., 2001) and Stout's theoretical curve. Transport rates 275 and distances reported in the RWEQ original graph have been normalized 276 by $Q_{m}$ and $F_{c}$, respectively. Maximum transport in Fig. 2 in Stout's (1990) original 277 publication occurs around $x / s=4.5$ (this is, $F_{c}$ is roughly $4.5 \mathrm{~s}$ ). Thus $x / s$ values

278 have been divided by 4.5 to obtain distances normalized by $F_{c}$. The agreement 279 between the two curves is significant, but Stout's equation tends to overestimate 280 transport in the area where $F<F_{c}$ (or vice versa: RWEQ underestimates transport). 281 The equations proposed by Bauer and Davidson-Arnott (2003) are discussed in 282 Section 5.2.

283

284 2.2.2. Beaches

285 Svasek and Terwindt (1974) introduced the first explicit reference to the 286 importance of fetch distances on beaches, and suggested a minimum critical fetch 
287 distance of 10-20 $\mathrm{m}$ for onshore winds to reach maximum transport. However, 288 they did not distinguish the cause of the observed fetch effect. Experiments 289 by Nordstrom and Jackson (1993) are instructive because of their efforts to 290 analyze the combined effect of variables such as moisture content, mean grain 291 size, beach slope and fetch distances amongst others. They compared aeolian 292 transport during five high-velocity wind events (from 8.5 to $15.9 \mathrm{~m} \mathrm{~s}^{-1}$ ) on an 293 estuarine beach in Delaware Bay (New Jersey, US), and demonstrated that short 294 available fetch distances on narrow beaches can counteract the potential of higher 295 wind speeds to transport large amounts of sediment. Sand trapped during periods 296 of oblique winds was over 20 times greater than any day with onshore winds, 297 because oblique winds created an available fetch distance $(\approx 37 \mathrm{~m})$ nearly double 298 that for onshore winds $(\approx 18 \mathrm{~m})$. Increases in fetch distances were able to partially 299 overcome surface limitations such as higher moisture content or larger mean grain 300 sizes. Independent experiments carried out by Bauer (1991) (Monterey Bay, 301 California, US) and Davidson-Arnott and Law (1990) (Long Point, Lake Erie, 302 Canada) related the increase of sediment transport rates landward from the 303 shoreline with the existence of upwind sand sources and beach width, respectively. 304 At Long Point, winds just above the threshold achieved maximum transport rates at 305 approximately $10-15 \mathrm{~m}$, but saltation did not fully develop over a dry surface with 306 stronger winds of about $14 \mathrm{~m} \mathrm{~s}^{-1}$ because the $35 \mathrm{~m}$ wide beach did not provide 307 enough fetch distance.

308 The fetch effect may be small for low wind events and dry, well-sorted fine sands

309 (Fig. 1).Jackson and Cooper, 1999 and Lynch et al., 2008 report on the 310 insignificant role of the fetch effect with onshore winds around 8 and $10 \mathrm{~m} \mathrm{~s}^{-1}$, 
311 respectively blowing over dry, well sorted sediments $(0.17 \mathrm{~mm}$ mean grain size).

312 Although the strength of the control exerted by the fetch effect varies both

313 temporally and spatially, there is strong evidence supporting the existence of long

314 critical fetch distances in many common beach situations, specifically in relation to

315 moisture content and other supply-limiting factors (Van der Wal, 1998, Davidson-

316 Arnott and Dawson, 2001, Davidson-Arnott et al., 2005a,Davidson-Arnott et al.,

317 2005b and Davidson-Arnott et al., 2005c). Thus, for example, the

318 measured $F_{c}$ ranged from 80 to $200 \mathrm{~m}$ (Davidson-Arnott et al., 2008) and in

319 another study from 50 to $150 \mathrm{~m}$ (Bauer et al., 2009).

\section{3. The physics of the fetch effect}

323 3.1. Evolution of saltation

324 Numerical models of sand transport by wind have been able to simulate many of

325 the physical processes involved in saltation (Ungar and Haff, 1987, Werner,

326 1990, McEwan and Willetts, 1993, Shao and Li, 1999 and Lu and Dong, 2007),

327 including the time and length required to achieve a steady state (Anderson and

328 Haff, 1991 and Zeng, 2008).Spies and McEwan (2000) confirmed some of the

329 characteristics of saltation observed by previous researchers (e.g., Bagnold,

330 1941, Anderson and Haff, 1988 and Shao and Raupach, 1992).

331 The existence of a critical fetch distance is inherent to the evolution of saltation and

332 can be explained as follows: when wind with a speed greater than the threshold of

333 movement starts blowing over an erodible surface there is an initial rapid increase

334 of $\mathrm{Q}$ with distance from the upwind boundary over the first few metres as a 
consequence of the rapid cascade of particle mobilization and entrainment into the

336 air flow. Aerodynamic entrainment of particles is the most important process when

337 saltation begins. The wind lifts, accelerates, and transmits kinetic energy to the

338 grains, which travel following trajectories of different heights and lengths depending

339 on the wind velocity ( Dong et al., 2009). Acceleration of grains is such that their

340 impact velocity is almost equal to the wind velocity at the highest point of the

341 trajectory (Svasek and Terwindt, 1974). The increase in particle momentum allows

342 the impact of saltating grains to eject more particles into the air or roll them along

343 the surface, which quickly shifts the dominant entrainment process to grain impact

344 (Nickling, 1988 and Anderson and Haff, 1991). The number of grains in motion

345 growths exponentially with distance, as in a snow avalanche (Chepil, 1957). As the

346 particle flux increases it modifies the flow, creating an internal boundary layer that

347 grows downwind, and reducing the wind speed near the bed. The result is a self-

348 balancing mechanism responsible for limiting the growth of mass transport to a

349 stable value (Fryrear and Saleh, 1996) in which the particle ejection rate eventually

350 reaches an equilibrium state at some point in distance downwind ( Shao and

351 Raupach, 1992 and Fryrear et al., 2000).

353 3.2. Long fetch distances in field situations

354 With dry, uniform sand the avalanching process and accompanying self-balancing

355 mechanism occurs within a few metres to a few tens of metres depending on wind

356 speed. Field studies indicate that supply-limiting factors are primarily responsible

357 for increasing the $F_{c}$ over that measured for dry, uniform sediment. In general

358 terms, a reduced rate of grain ejection from the bed would increase the 
359 time/distance needed to accumulate the mass of loose, dry sediment that defines

360 the limit of aeolian transport for a particular wind speed. In the case of agricultural

361 soils, long critical fetch distances relate to the space and time it takes to erode

362 particles from earth clods. In the case of moist sand on the beach surface, the

363 space and time is related to the reduced rate of ejection by saltating particles and

364 the distance needed to accumulate the equilibrium mass of dry sediment

365 downwind.

366

367 3.2.1. Agricultural fields and soil conditions

368 A complete description of the fetch effect should incorporate knowledge of the soil

369 physical state (Gillette et al., 1996) because soil clods and crusts are determinant

370 factors in limiting the quantity of erodible material (Fryrear and Saleh, 1996). The

371 RWEQ requires a large number of 'soil inputs'. Percentages of sand, silt, organic

372 matter and other variables are introduced to quantify, amongst others, the soil crust

373 factor, which reflects crust development and its influence on soil erosion by wind.

374 Maximum soil loss is often related to smooth, bare, and unprotected dry fields

375 (Fryrear et al., 2000).

376 Gillette et al. (1996) propose two mechanisms on top of the avalanching processed

377 (Section 3.1) that could explain critical fetch distances up to hundreds of metres.

378 The first mechanism is based on ideas developed by Owen (1964), who described

379 the modification of flow imposed by saltation outside of the region of particle motion

380 as analogous to a solid roughness. The increase in apparent roughness height

381 leads to an increase in friction velocity and momentum transfer to the surface. This

382 in turn increases saltation, which leads the system into a positive "aerodynamic 
383 feedback". This feedback was not found in all locations studied by Gillette et al. 384 (1996), who introduced a third mechanism based on the resistance of soil to

385 erosion. Soil aggregates (including crusts) are destroyed by sandblasting in

386 proportion to the quantity of material being transported by the wind (Fryrear and

387 Saleh, 1996). As sandblasting increases downwind the non-erodible portion of the

388 soil decreases and more wind momentum goes to transporting particles. The same

389 wind stress is able to transport more sediment as distance increases from the

390 leading edge because the decrease in surface area covered by crusts changes the

391 soil resistance to wind erosion. According to Gillette et al. (1996), avalanching

392 dominates at the leading edge of erodible material but it is a residual effect for

393 distances of more than $50-100 \mathrm{~m}$. Threshold friction velocity depends on soil

394 composition and sediment size distribution, while friction velocity is a function of

395 topography, pressure gradients and roughness. The fetch effect is controlled

396 primarily by the "aerodynamic feedback" in non-aggregated homogenous sand

397 surfaces. Non-homogenous size distributions and soil aggregation yield different

398 threshold velocities, and thus soil resistance to erosion becomes the primary

399 control.

400

401 3.2.2. Beaches: moisture and other complicating factors

402 Aerodynamic feedback is probably a second order mechanism in coastal areas,

403 and the effect of crusts may only be occasionally important on beaches (Davidson-

404 Arnott and Dawson, 2001). Small amounts of moisture, on the other hand, are

405 often present on beach sediments, and it seems likely that it plays a significant role

406 in increasing critical fetch distances in these environments. At the time this paper 
was submitted there were no published results from wind tunnel experiments

408 specifically dealing with the interaction between moisture and fetch distance. Given

409 a tunnel long enough, an experiment with a wet uniform sediment surface would be

410 feasible in order to provide information on the distance needed for a supply-limited

411 environment to achieve equilibrium. Due to the lack of laboratory data, our

412 knowledge relies on the results of fieldwork experiments that describe complex

413 relationships between variable wind speeds and directions, strong spatial and

414 temporal patterns of superficial moisture content, and changing fetch distances

415 (Davidson-Arnott and Dawson, 2001, Davidson-Arnott et al., 2005b, Davidson-

416 Arnott et al., 2005c, Davidson-Arnott et al., 2008, Bauer et al., 2009, Davidson-

417 Arnott and Bauer, 2009 and Walker et al., 2009). Although we can determine the

418 role of the fetch effect in the development of transport under relatively simple

419 conditions, this may be masked or eliminated when complexities such as sharp-

420 crested berms, varying sediment sizes, and non-homogenous moisture add to a

421 system already in disequilibrium. However, there is sufficient evidence suggesting

422 that wet surfaces are indeed responsible for increases on critical fetch distances up

423 to several hundreds of metres.

424 Moisture increases the threshold of wind speed able to entrain sediment (Cornelis

425 and Gabriels, 2003 and Wiggs et al., 2004b). The reduction of the number of grains

426 ejected by fluid stress decreases the number of grains dislodged by the impact of

427 saltating particles, which slows down the rate of transport increase downwind.

428 Wind gusts may be enough to overcome surface moisture and generate sand

429 streamers with fetch distances close to $30 \mathrm{~m}$ and moisture content less than $10 \%$

430 (Davidson-Arnott and Dawson, 2001). 
431 Saltation at the beach is often highly intermittent as a result of fluctuations in wind

432 speed, and wetting and rapid drying of surficial sediments (Bauer et al., 2009). The

433 simple gradual growth in the mean mass flux with distance downwind from the

434 edge of erodible material that is evident in trap data collected over tens of minutes

435 (Fig. 3a) may be produced by an increase in the frequency of instantaneous

436 transport events downwind (Fig. 3b). In this situation the $F_{c}$ associated with

437 individual transport events may be less than half of that for the integrated time

438 series ( Davidson-Arnott et al., 2005c). In the field, a steady state of transport rate

439 on the beach may never be achieved because of additional complexities such as

440 the presence of different sediment sizes (Bauer, 1991), which may make isolation

441 and modelling of the fetch effect more difficult. Boundary layer development

442 downwind produces lower shear-stresses and interacts with the fetch effect to

443 regulate the evolution of transport (Bauer et al., 2009). In addition, as wind

444 approaches the back of the beach the effects of sheltering by vegetation in the

445 embryo dune and stagnation of the flow due to the presence of the foredune (Hesp

446 et al., 2005) commonly reduce transport rates and enhance deposition in the dune

447 toe area (as shown by trap 5 in Fig. 3a).

449 4. Implications of long critical fetch distances: geometric considerations

451 The absence of spatial constraints on the angle of wind approach in natural areas

452 gives rise to a series of tradeoffs related to the fetch effect, wind direction, and

453 dimension of the erodible surface over which the wind is blowing. For example, in

454 arid and semi-arid regions with mesquite vegetation flux increases along streets in 
455 the windward direction, and the shape and orientation of large gaps created by

456 vegetation distribution are key in controlling aeolian flux (Okin et al., 2006). In the

457 Great Plains, protection of soil from erosion can be achieved by considering simple

458 geometrical relationships amongst field dimensions, wind break height and

459 orientation, and the prevailing wind direction. According to Chepil et al. (1964), the

460 amount of erosion on any field can be determined from the longest distance across

461 the field along the prevailing wind erosion direction, $F_{m}$. This can be obtained from

462 the width of the field strip $\left(\mathrm{W}_{\mathrm{f}}\right)$ and the angle of deviation of the prevailing wind

463 erosion direction from right angles to the field strip (a):

464

$465 \quad F_{m}=W_{f} / \cos \alpha$

466

467 Similarly, the relation between angle of wind approach and beach width determines

468 the available fetch distance between the swash limit and the vegetated surface at

469 the back of the beach. As explained in Section 2.2.2, transport during strong

470 onshore winds can be limited by short fetch distances on narrow beaches. This

471 decreases the amount of sediment delivered to the coastal dune, because

472 sediment eroded from the beach is the primary source of material for foredune

473 building (Psuty, 1988). There are many instances where the beach width may be

474 substantially reduced due to nearshore processes such as wave run up and storm

475 surge (Ruz and Meur-Ferec, 2004 and Bauer et al., 2009) or tidal elevation

476 (Nordstrom and Jackson, 1992). Given that the critical fetch distance increases

477 with wind speed (e.g., Dong et al., 2004) and that the rate of transport is commonly 
478 a cubic function of the wind drag (e.g., Bagnold, 1941) or wind velocity (e.g.,Dong

479 et al., 2004), overpredictions of sediment transport rates on many beaches are

480 likely to be related to fetch distance limitations during high energy onshore wind

481 events.

482 Where the beach width $\left(\mathrm{W}_{\mathrm{b}}\right)$ is narrower than $\mathrm{F}_{\mathrm{c}}$ for a particular onshore wind an

483 oblique angle of wind approach increases the fetch distance and therefore the

484 potential sediment transport rate. However, beach-dune geometry dictates that the

485 actual deposition in the vegetated foredune per unit distance alongshore

486 decreases as the wind becomes more oblique as a function of the cosine of the

487 wind angle (the cosine effect - see Davidson-Arnott and Dawson, 2001 and Bauer

488 and Davidson-Arnott, 2003). Thus sediment supply to the foredune per unit length

489 of dune $\left(Q_{1}\right)$ is defined as:

490

$491 Q_{l}=q_{c} \cos \alpha$

492

493 where $Q_{c}$ is the sediment transport rate at the top of the beach, and $\alpha$ is the angle

494 of wind to shore perpendicular (Fig. 4). Bauer and Davidson-Arnott 495 (2003) translate this concept into the following distances:

496

$497 \quad c=l \cos \alpha$

498

499 where I represents a unit alongshore length at the dune line mapped out by two 500 parallel streamlines of the wind field separated by the perpendicular 
501 distance c ( Fig. 4). As shown in Fig. 5, during alongshore winds the fetch distance

502 is at its maximum but transport across line $\mathrm{c}$ tends to zero. Onshore winds are not

503 subject of the cosine effect $(c=I)$ but short available fetch distances may limit

504 sediment input from the beach to the foredune. Thus, where $W_{b}<F_{c}$ there is a

505 complex tradeoff between increasing fetch distance with oblique winds and

506 decreased net transport into the dunes ( Bauer and Davidson-Arnott, 2003).

507

508 5. Modelling the fetch effect on beaches

509

510 While a framework incorporating beach geometry and the fetch effect (Bauer and

511 Davidson-Arnott, 2003) provides a basis for modelling sediment supply to coastal

512 dunes, two factors critical to its implementation are still unresolved: (1) a method

513 for calculating $\mathrm{F}_{\mathrm{c}}$; and (2) determination of a functional relationship describing the

514 increase in sediment transport with distance when $F<F_{c}$.

516 5.1. The critical fetch distance: a new threshold of concern?

517 The critical fetch distance is a threshold for equilibrium transport conditions

518 (Section 1). IfF $>F_{c}$ then saltation is fully developed and transport rates may be

519 calculated using traditional equations (e.g., Bagnold, 1941). If $F<F_{c}$ then the fetch

520 effect needs to be considered in the calculations ( Bauer and Davidson-Arnott,

521 2003). Thresholds are highly dynamic with complex interactions that dictate their

522 variability (e.g., Wiggs et al., 2004a and Wiggs et al., 2004b) and transport systems

523 usually require the combination of more than one threshold (Davidson-Arnott and

524 Bauer, 2009). The wind threshold to initiate sand movement can vary over periods 
525 as short as tens of seconds in response to drying of the surface by wind and

526 sunshine. In addition, $F_{c}$ increases with wind speed and moisture content but it is

527 not yet clear whether the maximum transport rate with moist sand is the same as

528 that for dry sand ( Davidson-Arnott et al., 2008). Thus, the question is whether

529 future research on the fetch effect should concentrate on associating different wind

530 speeds with particular values of $F_{c}$ or whether there are alternative ways to include

531 this concept into modelling (e.g., Davidson-Arnott et al., 2008 and Bauer et al.,

532 2009). The determination of $F_{c}$ may permit isolation of those events where

533 transport-limited equations can be applied, but it is of limited value if not

534 accompanied by a formulae for distance-related transport to be applied to those

535 events when $F<F_{c}$. One way around this dilemma may be to determine $F_{c}$ directly

536 from such a formula.

538 5.2. Transport as a function of distance

539 Computer simulations by Bauer and Davidson-Arnott (2003) suggest that the

540 particular equation for describing transport rate as a function of fetch distance has

541 significant impacts on the distribution of erosion-deposition processes across the

542 beach and predicted sediment supply to the foredunes. Bauer and Davidson-Arnott

543 (2003) examine four alternative equations (Fig. 2) that are applicable within the

544 area where $\mathrm{F}<\mathrm{F}_{\mathrm{c}}$ :

545

$546 \quad q(F, \alpha)=q_{m} \sin \left(\frac{\pi}{2} \frac{F}{F_{c}}\right)$ 
$548 \quad q(F, \alpha)=q_{m} 1 / 2\left[\sin \left(\pi\left(\frac{F}{F_{c}}-\frac{1}{2}\right)\right)+1\right]$

$550 \quad q(F, \alpha)=q_{m} 4 / \pi \tan ^{-1}\left(\frac{F}{F_{c}}\right)$

$552 q(F, \alpha)=q_{m} 2 / \pi \sin ^{-1}\left(\frac{F}{F_{c}}\right)$

554 Eq. (7) provides good agreement with findings in agricultural soils. Conceptually, it

555 is also the most consistent with the description of the saltating cascade (a steep

556 initial increase in the transport rate followed by a self-balancing mechanism) and

557 with Davidson-Arnott et al. (2008) who favour an exponential curve, although they

558 do not present any specific equation. However, it can only be applied if $F_{c}$ is

559 known.

560 Dong et al. (2004) express the relationship between sand flux and wind velocity (U)

561 as:

562

$563 Q=C\left(1-U_{t} / U\right)^{2} U^{3} \frac{\rho}{g}$

564

565 where $U_{t}$ is the threshold velocity measured at the same height as $U, \rho$ is the air

566 density, $g$ is the acceleration due to gravity, and $\mathrm{C}$ is a proportionality coefficient

567 that varies with $F$ as follows: 
$569 C=0.000306 F^{2 / 3}$

571 Dong et al. (2004) found good agreement between observed and calculated sand 572 flux for different velocities, but their equation does not predict the equilibrium stage

573 and has not yet been tested under natural conditions.

574 Although field data needs to be collected over a variety of wind speeds to verify its

575 suitability, an exponential equation such as the one proposed by Stout (1990 - see

576 Eq. (3)) has several practical advantages: (1) $F_{c}$ is implicitly defined as the distance

577 at which transport meets the asymptote marking a constant transport rate; (2)

578 considerable variations of $F$ around $F_{c}$ produce only small differences in calculated

579 transport rates because sediment fluxes are not very sensitive to fetch distances

580 close to the critical fetch.

581

582 6. Measuring the fetch effect in the field

583

584 Future short-term experiments on the fetch effect over the beach surface should

585 investigate the evolution of transport along the wind line under a variety of field

586 conditions, from 'simple scenarios' with dry sand and/or uniform moisture, to

587 'complex events' that could include rapid temporal and spatial variability of

588 moisture or other surface characteristics, and strong winds. Although short-term

589 studies can provide details about physical interactions between fetch and other

590 variables, the relative importance of results obtained from discrete measurements 
591 over the long term is unknown (Sherman, 1995). At a temporal scale of months to

592 years tradeoffs between the fetch effect, wind direction and beach width have

593 considerable influence on sediment supply to the foredune (Davidson-Arnott and

594 Stewart, 1987 and Davidson-Arnott and Law, 1996), and challenges remain in

595 developing appropriate instrumentation and ways to store and analyze data over

596 long temporal scales in order to overcome some of the limitations imposed by

597 synoptic observations. Recent advances in remote sensing techniques applied to

598 the study of coastal dunes may provide the means to acquire high spatial and

599 temporal resolution data over periods of time from hours to years, and thus

600 augment the efforts of traditional methods. For example, Lynch et al.

601 (2006) proposed a technique based on the use of digital cameras to measure fetch

602 distances from the wet swash area. Darke et al. (2009) tested the application of

603 video cameras to measure superficial moisture content using calibration curves

604 relating moisture with surface brightness. Delgado-Fernandez et al.

605 (2009) expanded the capabilities of previous systems and tested a remote sensing

606 technique based on digital single-lens reflex (SLR) cameras and ancillary

607 instrumentation to measure key aspects of the aeolian transport system at

608 Greenwich Dunes (Prince Edward Island National Park, Canada). This remote

609 sensing station provides continuous monitoring of surface moisture content, fetch

610 distances, shoreline position, vegetation cover, presence of snow-ice, wind speed

611 and direction, and transport intensity or erosion-deposition of sediment at the back

612 beach. The ability to observe the combined effect of factors driving sediment input

613 to the dunes may allow the characterization of important transport events through

614 the year and thus provide a means of testing models incorporating the fetch effect. 
617 The fetch effect has been measured in wind tunnel experiments and has long been

618 incorporated in studies of wind erosion of agricultural soils. While field observations

619 of the fetch effect on beaches are not as numerous as for agricultural fields, there

620 is now sufficient evidence of its potential significance for aeolian sediment transport

621 to coastal dunes to warrant its incorporation in long-term modelling. It is clear that

622 there are a number of mechanisms that can produce a fetch effect, but the most

623 significant ones seem to be related to the existence of factors that limit sediment

624 supply to the airstream. In agricultural soils the most significant factor appears to

625 be the presence of fines and the development of clods. On beaches fine particles

626 are generally absent and the fetch effect appears to be related primarily to the

627 presence of surface moisture.

628 There are a number of promising aspects of the study of the fetch effect that could

629 improve sediment transport calculations in coastal areas. Further research should

630 be carried out to refine the equation describing the increase of transport rate with

631 fetch distance, although the literature seems to favour an exponential function.

632 Studies of agricultural soils open interesting venues for aeolian coastal

633 geomorphologists interested in incorporating the fetch effect into modelling.

634 Although many aspects covered in the literature of agricultural fields are not

635 included in this review, the aim here was to highlight key findings that may apply to

636 beach-dune systems. Some of the physical explanations about long critical fetch

637 distances and the relation between field dimensions and wind erosion can be

638 translated to the coastal realm. 
639 The existence of critical fetch distances that greatly exceed the available source of

640 sediment needs to be taken into consideration when calculating potential sand

641 input to the dunes. Even on very wide beaches, the fetch effect may play a

642 significant role during strong wind events. Storms are usually associated with short

643 available fetch distances due to wave run up and beach inundation, as well as

644 increases in moisture levels on the upper beach (Nordstrom and Jackson,

6451992 and Ruz and Meur-Ferec, 2004). Under these conditions, only highly oblique

646 wind angles may be effective in moving sediment into the foredunes (Bauer et al.,

647 2009). Because sediment transport calculations at the meso-scale (e.g., Fryberger

648 and Dean, 1979) are usually based on wind speed to the power of 2 or 3,

649 overprediction is likely to occur during onshore storm events.

650 Knowledge about the fetch effect at the meso-scale needs to be coupled with

651 measurement of other key factors regulating the dynamics of aeolian transport

652 events delivering sediment to the foredunes. The loss of detail on the study of one

653 factor may be compensated with the advantages of looking at the system

654 holistically. Remote sensing systems allow observations of the frequency and

655 magnitude of events accounting for the majority of sediment moved through the

656 year and permit simultaneous measurements of key factors that can explain about

$65770-80 \%$ of the variability of the system (Delgado-Fernandez and Davidson-Arnott,

658 2009). The availability of digital cameras and video cameras coupled with improved

659 sensors for measuring sand transport should aid in refining our ability to

660 incorporate the fetch effect in modelling aeolian sediment transport in coastal

661 areas. 


\section{Acknowledgements}

663 This manuscript has enormously benefited from critical reviews and numerous

664 conversations with Robin Davidson-Arnott and Bernard Bauer. I am most grateful

665 to Jeff Ollerhead, lan Walker, and Hosahng Rew for providing challenging

666 questions on the problem of aeolian sediment transport at the beach at meso-

667 scale. Ray Kostaschuk and Bill Nickling thoroughly reviewed the manuscript and

668 gave substantial comments that greatly improved the final version. I am also

669 grateful for the feedback provided by two anonymous reviewers. Financial support

670 was provided by the Ontario Graduate Scholarship Program (Ministry of Training,

671 Canada).

672

673 References

674 Anderson, R.S. and Haff, P.K., 1988. Simulation of eolian saltation, Science, 820675823.

676 Anderson, R.S. and Haff, P.K., 1991. Wind modification and bed response during 677 saltation of sand in air, Acta Mech. (Suppl.), 21-52.

678 Arens, S.M., 1997. Transport rates and volume changes in a coastal foredune on a 679 Dutch Wadden island. J. Coast. Conserv. 3, 49-56.

680 Bagnold, R.A., 1941. The physics of blown sand and desert dunes, London, $681 \quad$ Methuen, 265 pp.

682 Bauer, B.O., 1991. Aeolian decoupling of beach sediments. Ann. AAG. 81, 290683 303.

684 Bauer, B.O. and Sherman, D.J., 1999. Coastal dune dynamics: Problems and 685 Prospects. In: Goudie, A.S., Livingstone, I. and Stokes, S. (EdS.), Aeolian 

104.

Bauer, B. O. and Davidson-Arnott, R. G. D., 2003. A general framework for modeling sediment supply to coastal dunes including wind angle, beach geometry and fetch effects, Geomorphology 49, 89-108.

691 Bauer, B.O., Houser, C.A. and Nickling, W.G., 2004. Analysis of velocity profile measurements from wind-tunnel experiments with saltation, Geomorphology $59,81-98$

Bauer, B.O., Davidson-Arnott, R.G.D., Hesp, P.A., Namikas, S.L., Ollerhead, J., Walker, I.J., 2009. Aeolian sediment transport on a beach: Surface moisture, wind fetch, and mean transport. Geomorphology 105, 106-116

Butterfield, G., 1999. Near-bed mass flux profiles in aeolian sand transport: highresolution measurements in a wind tunnel. Earth Surf. Proc. Land. 24, 393412.

Cornelis, W.M. and Gabriels, D., 2003. The effect of surface moisture on the entrainment of dune sand by wind: an evaluation of selected models. Sedimentology 50, 771-790.

Chepil, W.S., 1957. Width of field strips to control wind erosion. Kan. AEL Bull. No. 92.

Chepil, W.S. and Milne, R.A., 1939. Comparative study of soil drifting in the field and in a wind tunnel, Sci. Agr. 19, 249-257.

Chepil, W.S., Siddoway, F.H., and Armbrust, D.V., 1964. Prevailing wind erosion direction. J. Soil Water Conserv. 19, 67-71. 
Darke, I., Davidson-Arnott, R.G.D. and Ollerhead, J., 2009. Measurement of beach surface moisture using surface brightness. J. Coast. Res. 25, 248-256.

711 Davidson-Arnott, R.G.D. and Stewart, C.J., 1987. The effects of longshore sand waves on dune Erosion and Accretion, Long Point, Ontario. In: Proc. Can.

Davidson-Arnott, R.G.D. and Law, M.N., 1990. Seasonal patterns and controls on sediment supply to coastal foredunes, Long Point, Lake Erie. In: Nordstrom, K.F., Psuty, N.P. and Carter, R.W.G. (EdS.), Coastal Dunes: Form and Process. John Wiley \& Sons, 177-20.

Davidson-Arnott, R.G.D. and Law, M.N., 1996. Measurement and prediction of long-term sediment supply to coastal foredunes. J. Coast. Res. 12, 654-663.

Davidson-Arnott, R.G.D. and Dawson, J.D., 2001. Moisture and fetch effects on rates of aeolian sediment transport, Skallingen, Denmark. In: Proc. Can. Coast. Conf., CCSEA, 309-321.

Davidson-Arnott, R.G.D., Bauer, B.O., Hesp, P.A., Namikas, S.L., Ollerhead, J., and Walker, I.J., 2005a. Moisture and fetch effects on aeolian sediment transport rates during a fall storm, Greenwich Dunes, Prince Edward Island. In: Proc. Can. Coas. Conf., CCSEA, Compact Disk.

Davidson-Arnott, R.G.D., MacQuarrie, K. and Aagaard, T., 2005b. The effect of wind gusts, moisture content and fetch length on sand transport on a beach. Geomorphology 63, 115-129.

Davidson-Arnott, R.G.D., Ollerhead, J., Hesp, P.A., and Walker, I.J., 2005c. Spatial and temporal variability intensity of Aeolian transport on a beach and foredune. In: Proc. Coastal Sediments 2003. New York, ASCE, 14 p. 
733 Davidson-Arnott, R.G.D., Yang, Y., Ollerhead, J., Hesp, P.A. and Walker, I.J.,

754 Fryrear, D.W. and Saleh, A., 1996. Wind erosion: field length. Soil Sci. 161, 398755 404. 
756 Fryrear, D. W., Bilbro, J. D., Saleh, A., Schomberg, H., Stout, J. E., and Zobeck, T. M., 2000. RWEQ: Improved Wind Erosion Technology. J. Soil Water Conserv. 55, p. 183

759 760

761

762

763

764

765

766

767

768

769

770

771

772

773 774

775

776

777

778

779

Fryrear, D.W., Sutherland, P.L., Davis, G., Hardee, G. and Dollar, M., 2001. Wind erosion estimates with RWEQ and WEQ, 760-765, In: Stout, D.E., Mohtar, R.H. and Steinhardt, G.C. (Eds.) Sustaining the Global Farm, p. 1169

Gillette, D.A., Herbert, G., Stockton, P.H. and Owen, P.R., 1996. Causes of the fetch effect in wind erosion, Earth Surf. Proc. Land. 21, 641-659.

Hansen, Z.K. and Libecap, G.D., 2004. Small farms, externalities, and the Dust Bowl of the 1930s. J. Polit. Econ. 112, 665-694.

Hesp, P.A., Davidson-Arnott, R.G.D., Walker, I.J. and Ollerhead, J., 2005. Flow dynamics over a foredune at Prince Edward Island, Canada. Geomorphology 65, 71-84.

Horikawa, K., Hotta, S. and Kraus, N.C., 1986. Literature review of sand transport by wind on a dry sand surface, Coas. Eng. 9, 503-526.

Jackson, D.W.T. and Cooper, J.A.G., 1999. Beach fetch distance and aeolian sediment transport, Sedimentology 46, 517-522.

Lu, P. and Dong, Z., 2007. Numerical simulation of a wind-sand flow. J. Earth Sci. 1, 154-162.

Lyles, L., 1977. Wind erosion: processes and effect on soil productivity. Trans. ASAE, 20, 880-884.

Lynch, K., Jackson, D.W.T. and Cooper, A.G., 2006. A remote-sensing technique for the indentification of aeolian fetch distance. Sedimentology 53, 13811390. 
Lynch, K., Jackson, D.W.T. and Cooper, A.G., 2008. Aeolian fetch distance and secondary airflow effects: the influence of micro-scale variables on mesoscale foredune development. Earth Surf. Proc. Land. 33, 991-1005.

McEwan, I. K. and B. B. Willetts (1993). Adaption of the near surface wind to the development of sand transport. J. Fluid Mech. 252, 99-115.

Namikas, S.L. and Sherman, D.J., 1995. A review of the effects of surface moisture content on aeolian sand transport. In: V.P. Tchakerian (Ed.), Desert Aeolian

Nickling, W.G., 1988. The initiation of particle movement by wind, Sedimentology Processes. Chapman and Hall Ltd., London, 269-293.

Nickling, W.G. and Davidson-Arnott, R.G.D., 1990. Aeolian sediment transport on $35,499-511$. beaches and coastal sand dunes. In: Davidson-Arnott, R.G.D. (Ed.), Proc.

794 Nickling, W.G., 1994. Aeolian sediment transport and deposition. In: Pye, K. (Ed.), 795 Sediment Transport and Depositional Processes Blackwell Scientific Symposium on Coastal Sand Dunes, National Research Council of Canada, $1-35$. Publications Ltd., 397 pp.

Nordstrom, K. F. and Jackson, N. L., 1993. The role of wind direction in eolian transport on a narrow sand beach, Earth Surf. Proc. Land. 18, 675-685. elevation changes on aeolian transport on an estuarine beach, Sedimentology 39, 769-778. 
802 Okin, G. S., Gillette, D. A. and Herrick, J.E., 2006. Multi-scale controls on and 803 consequences of aeolian processes in landscape change in arid and semi804 arid environments, J. Arid Environ. 65, 253-275.

805 Owen, P.R., 1964. Saltation of uniform grains in air, J. Fluid Mech. 20, 225-242.

806 Pye, K., 1983. Coastal Dunes. Prog. Phys. Geog. 7, 531-597.

807 Ruz, M.H. and Meur-Ferec, C., 2004. Influence of high water levels on aeolian 808 sand transport: upper beach/dune evolution on a macrotidal coast, Wissant $809 \quad$ Bay, northern France. Geomorphology 60, 73-87.

810 Shao, Y. and Raupach, M.R., 1992. The overshoot and equilibrium of saltation, J. Geophys. Res. 97, 20559-20564.

812 Shao, Y. and Li, A., 1999. Numerical modelling of saltation in the atmospheric 813 surface layer. Bound.-Lay. Meteorol. 91, 199-225

814 Spies, P. J. and I. K. McEwan, 2000. Equilibriation of saltation. Earth Surf. Proc. 815 Land. 25, 437-453.

816 Stout, J.E. 1990. Wind erosion within a simple field. T. ASAE 33, 1597-1600.

817 Stout, J.E. and Zobeck, T.M., 1996. The Wolfforth field experiment: a wind erosion 818 study, Soil Sci. 161, 616-632

819 Stout, J.E. and Zobeck, T.M., 1997. Intermittent saltation, Sedimentology 44, 959$820 \quad 970$.

821 Svasek, J.N. and Terwindt, J.H.J., 1974. Measurement of sand transport by wind 822 on a natural beach, Sedimentology $21,311-322$.

823 Ungar, I. E. and P. K. Haff, 1987. Steady state saltation in air. Sedimentology 34, 824 289-299. 
825 van der Wal, D., 1998. Effects of fetch and surface texture on aeolian sand 826 transport on two nourished beaches, J. Arid Environ. 39, 533-547.

827 Van Pelt, R.S., Zobeck, T.M. and Potter, K.N., 2001. Validation of the Wind Erosion 828 Equation (WQE) for discrete periods and of the Wind Erosion Stochastic 829 Simulator (WESS) for single events. In: Ascough, J.C. and Flanagan, D.C. 830 (Eds.), Soil Erosion Research for the 21st Century, Proc. Int. Symp., $831 \quad$ ASABE, pp. 683-686.

832 Walker, I. J., Hesp, P.A., Davidson-Arnott, R.G.D., Bauer, B.O., Namikas, S.L., 833 Ollerhead, J., 2009. Responses of three-dimensional flow to variations in the

845 Zeng, X.J., 2008. Simulation, prediction and experiment on windblown sand movement and aeolian geomorphology. Proc. 12th Asian Cong. Fluid Mech., Daejeon, Korea. 


\section{Table footnotes}

${ }^{1}$ Researchers working in agricultural soils define the critical length as the point in
distance where $63.2 \%$ of the transport capacity for a given wind over a specific
soil surface has been reached (e.g., Fryrear and Saleh, 1996; Fryrear et al.,
2000; Stout, 1990).
${ }^{2}$ The RWEQ computational models are used by a number of agencies and
institutions to model the amount of erosion and soil loss by wind, such as the
United States Department of Agriculture or the Natural Resources Conservation
Service (Van Pelt, 2001). A detailed comparison between the WEQ and the
RWEQ can be found in Fryrear et al. (2001).

850

851 List of figures
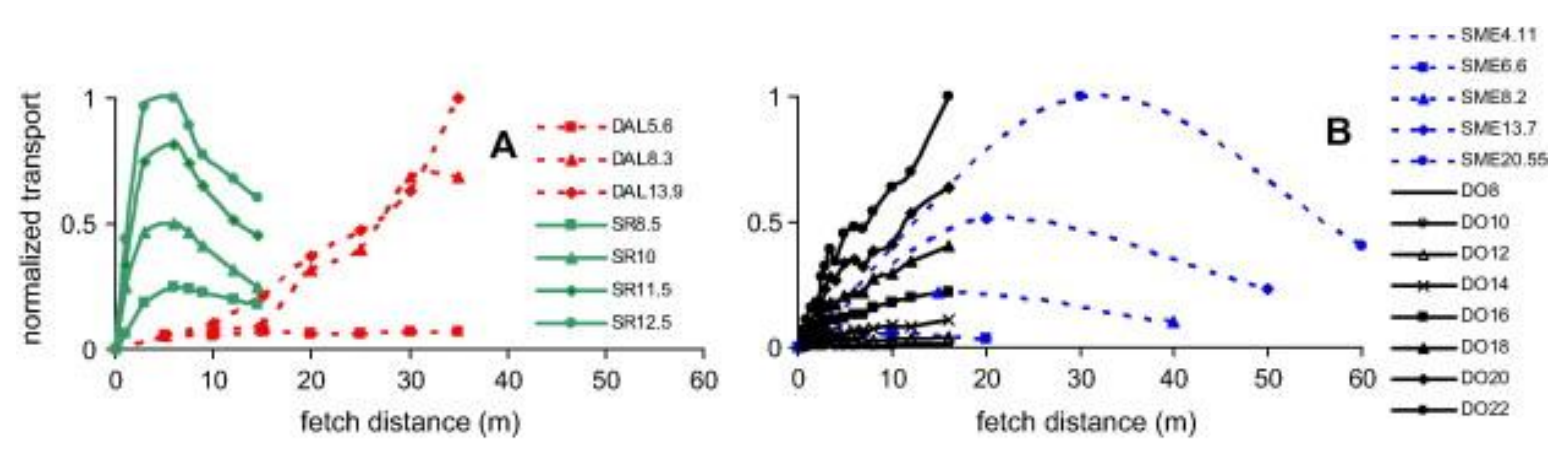

Fig. 1. Evolution of transport downwind from the leading edge of erodible material for different wind velocities. (A) SR: Shao and Raupach (1992); DAL: Davidson-Arnott and Law (1990). (B) DO: Dong et al. (2004); SME:Spies and McEwan (2000). Note that the maximum wind speed in SR $\left(12.5 \mathrm{~m} \mathrm{~s}^{-1}-\mathrm{A}\right)$ is one of the lowest values reported by DO (B). 


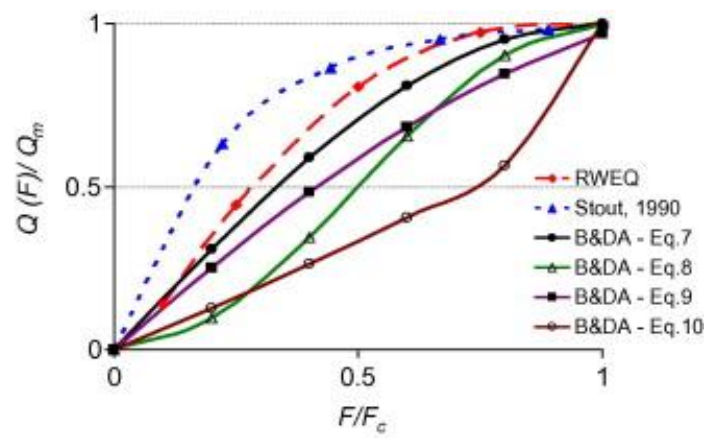

Fig. 2. Comparison of the shape of different transport curves parameterizing the increase of transport rates as a function of increasing fetch distances. Data for the RWEQ has been extracted from Fryrear et al. (2001). B\&DA stands for Bauer and Davidson-Arnott (2003).

853

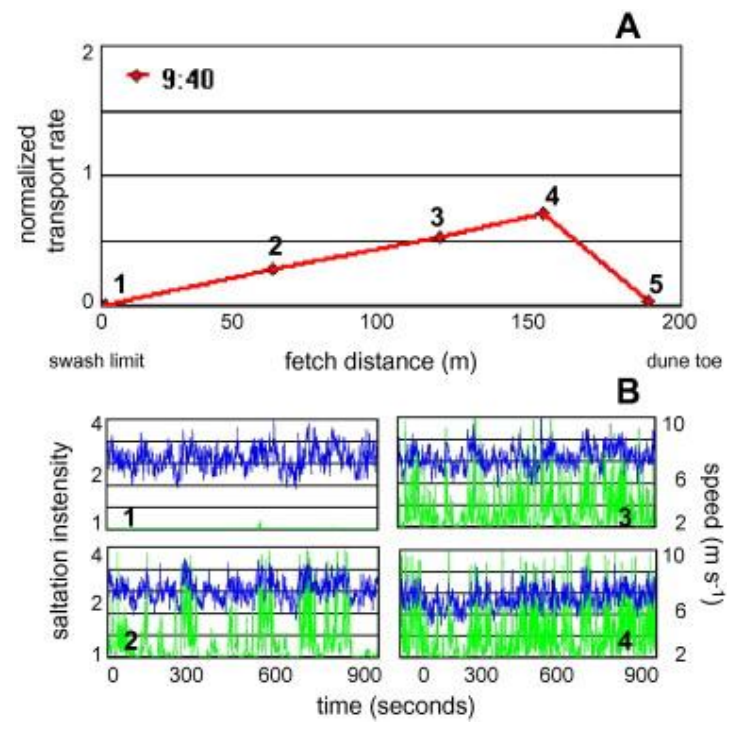

Fig. 3. (A) Evolution of mass flux downwind as recorded by integrating traps (20 min runs); (B) Instantaneous records of safires measuring at trap locations showing an increase in the frequency and magnitude of saltation events downwind (Davidson-Arnott et al., 2008). 


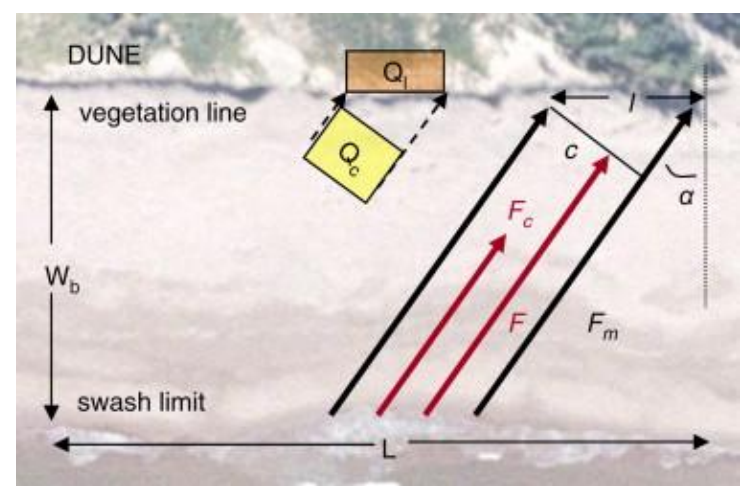

Fig. 4. Terminology associated with the fetch effect at a beach-dune system. $F_{m}$ : maximum fetch distance; $F_{c}$ : critical fetch distance; $\alpha$ : angle of wind approach from shore perpendicular; $\mathrm{W}_{\mathrm{b}}$ : beach width; $\mathrm{L}$ : beach length; I: unit alongshore length at the dune line mapped out by two parallel streamlines of the wind field, separated by the perpendicular distance $c ; Q_{\mid}=$sediment deposition per unit length of dune; $Q_{c}=$ sediment transport rate at the top of the beach (modified from Davidson-Arnott and Dawson, 2001 and Bauer and Davidson-Arnott, 2003).

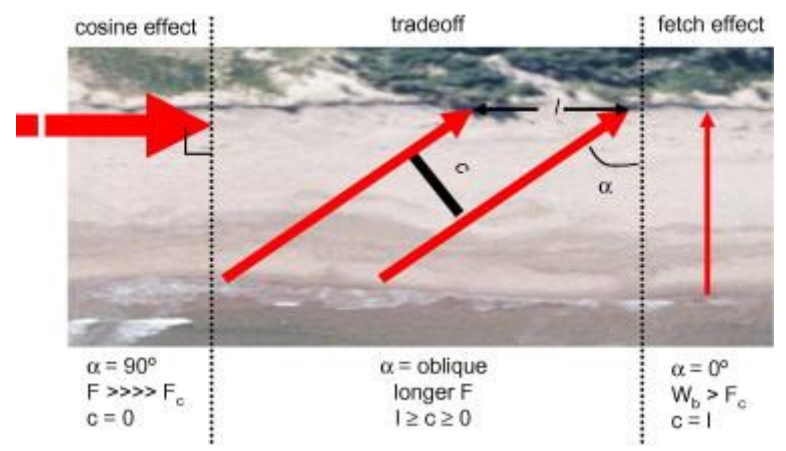

Fig. 5. Effect of wind angle, fetch effect, cosine effect and beach width on narrow beaches. Symbols are defined in Fig. 4. 